University Press Scholarship Online

\title{
Oxford Scholarship Online
}

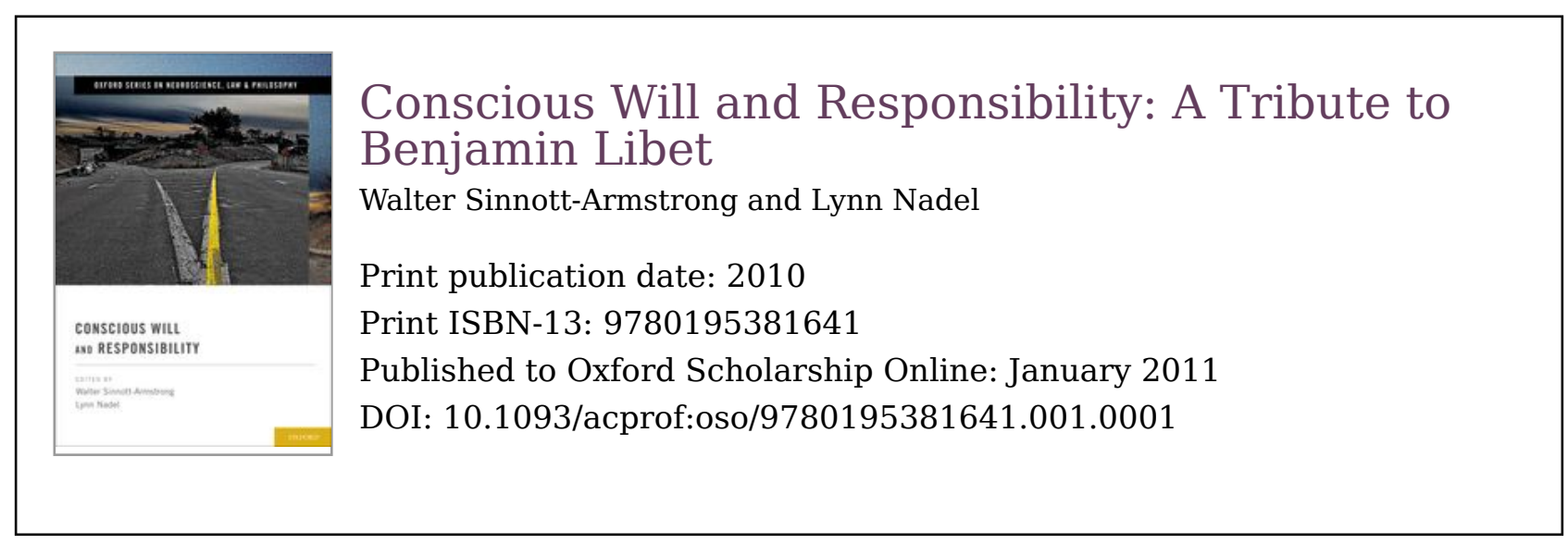

\section{Forward Modeling Mediates Motor Awareness}

\author{
Francesca Carota \\ Michel Desmurget \\ Angela Sirigu
}

DOI:10.1093/acprof:oso/9780195381641.003.0010

\begin{abstract}
Keywords
This chapter focuses on the issue of motor awareness. It addresses three main questions: What exactly are we aware of when making a movement? What is the contribution of afferent and efferent signals to motor awareness? What are the neural bases of motor awareness? It reviews evidence that the motor system is mainly aware of its intention. As long as the goal is achieved, nothing reaches awareness about the kinematic details of the ongoing movements, even when substantial corrections have to be implemented to attain the intended state. The chapter also shows that motor awareness relies mainly on the central predictive computations carried out within the posterior parietal cortex. The outcome of these computations is contrasted with the peripheral reafferent input to build a veridical motor awareness. Some evidence exists that this process involves the premotor areas.
\end{abstract}

Keywords: motor awareness, movements, afferent signals, efferent signals, central predictive computations 
According to the Merriam-Webster's Collegiate Dictionary, consciousness defines "the quality or state of being aware especially of something within oneself." Following Watson's behaviorist revolution (Watson, 1913), consciousness was deemed nonscientific and its investigation was considered to be the preserve of theologians and philosophers like Descartes (1641/1992), Spinoza (1677/1994), or Bergson (1888/2007). This view eroded recently in the face of neuropsychological evidence suggesting that consciousness is not a spiritual trait, but an emerging property of neural activities. When the brain is damaged our capacity to generate conscious intentions to act can be severely impaired (Haggard, 2005). At the same time, our ability to be aware of our motor responses can be dramatically altered (Frith, Blakemore, \& Wolpert, 2000). For instance, some patients can become spectator of alien movements they produce without will (Scepkowski \& Cronin-Golomb, 2003). Others can lose the subjective experience of wanting to move (Sirigu et al., 2004). Others can obstinately claim that they are moving a paralyzed arm (Orfei et al., 2007). Others can report movements in a limb that no longer exists (Ramachandran \& Hirstein, 1998). Others can be tricked into identifying as their own, a movement performed by someone else (Sirigu, Daprati, Pradat-Diehl, Franck, \& Jeannerod, 1999). Others can lose their ability to generate conscious motor images of their actions (Sirigu, Duhamel, Cohen, Pillon, Dubois, \& Agid, 1996), etc.

Identification of awareness as a valid object for scientific exploration triggered a large number of studies in normal subjects. A first line of research investigated our ability to become aware of our intentions to move (Haggard, 2005, 2008). It was mainly found that the conscious experience of intending to move occurs after the onset of brain activity (Libet, Gleason, Wright, \& Pearl, 1983; Haggard \& Eimer, 1999; Sirigu et al., 2004). In another group of experiments, researchers focused on "action-effects" mismatches. In this type of paradigm, the effects of an action are manipulated in such a way that they no longer match the initial intention of the subject. It was shown that reafferent sensations associated with the ongoing movement were widely unavailable to consciousness (Goodale, Pelisson, \& Prablanc, 1986; Wolpert, Ghahramani, \& Jordan, 1995; Fourneret \& Jeannerod, 1998). This result conflicts partially with other evidence showing that the way we consciously perceive our movements is not independent of action execution. In other words, although sensory-motor mismatches do not always reach consciousness, the sensory consequences of our actions can deeply influence the subjective experience attached to the realization of these actions (Haggard, Clark, \& Kalogeras, 2002; Moore \& Haggard, 2008).

The present chapter focuses on the issue of motor awareness. Our goal is to tackle some of the inconsistencies above by addressing three main questions: (1) What exactly are we aware of when making a movement? (2) What is the contribution of afferent and efferent signals to motor awareness? (3) What are the neural bases of motor awareness? (p.98) 
What Exactly Are We Aware of When Making a

Movement?

Most of the functioning of the motor system occurs without awareness. Some examples of this fact can be found in postural regulations (Wing, Flanagan, \& Richardson, 1997), nonverbal communication skills (Dijksterhuis \& Bargh, 2001), eye movements during perception of complex scenes (Yarbus, 1967), and on-line control of goal-directed movements (Desmurget \& Grafton, 2003). Other examples lie in several studies showing that the motor system can remain unaware of large sensory distortions occurring during the movement. For instance, Turner and colleagues required human subjects to

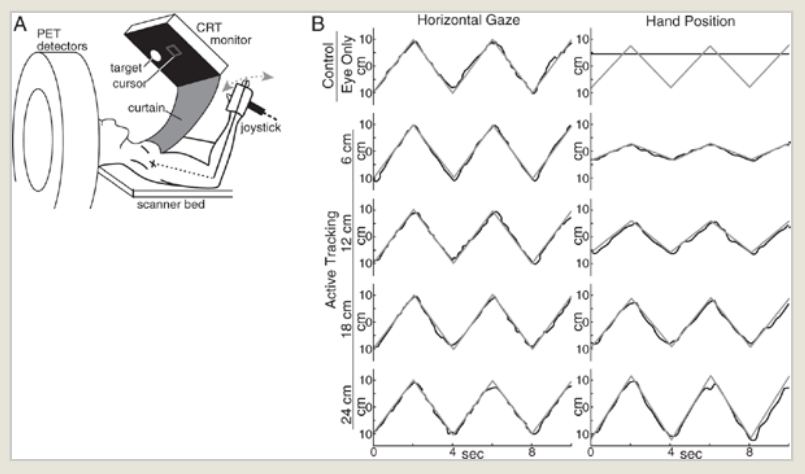

Figure 9.1 (A) Experimental apparatus. The subjects were supine in the PET scanner with their right hand holding a joystick. A computer monitor was suspended over the eye of the subject. The task was to track a computer-driven target (circle) with a joystick-driven box (square). (B) Behavioral recording corresponding to $10 \mathrm{~s}$ of data for different gain values of the joystick. Changes in gain were not detected by the subjects. (Reprinted with permission from Turner et al. 2003). perform a tracking task (Fig.

9.1) (Turner, Desmurget, Grethe, Crutcher, \& Grafton, 2003). During task performance, a white circle moved horizontally across a monitor at constant speed $(10 \mathrm{~cm} / \mathrm{s})$ between endpoints $20 \mathrm{~cm}$ apart. The circle reversed direction of movement with no delay on reaching left and right endpoints. Subjects were instructed to keep the circle within a red square controlled by a hand-held joystick. On different sessions, the gain of the relationship between joystick movement and cursor displacement was modified in such a way that joystick displacements of $6,12,18$, and $24 \mathrm{~cm}$ produced cursor displacements of $20 \mathrm{~cm}$. None of the 13 subjects involved in the study exhibited awareness that the joystick-to-cursor relation changed from session to session. A similar observation was reported by Wolpert and colleagues during a planar point-to-point reaching task (Wolpert et al., 1995). The subjects received a visual feedback of their movement through a mirror positioned above the pointing table. For the purpose of the study, the feedback was altered so as to increase the perceived curvature of the movement (Fig. 9.2). 
The perturbation was zero at both ends of the movement and reached its maximum $(4 \mathrm{~cm})$ at the midpoint of the movement. This distortion was not consciously perceived by the subjects, who progressively restored straight paths in the visual space by generating curved hand movements in a direction opposite to the (p.99)

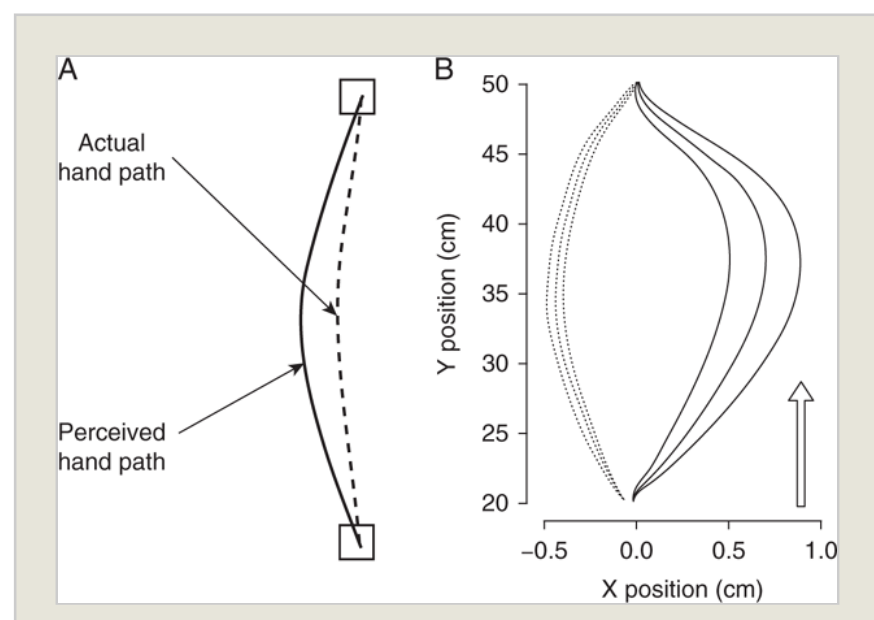

Figure 9.2 (A) Illustration of the visual distortion. (B) Control trajectories (dotted lines) compared with postadaptation traces (solid lines). The arrow shows movement direction. (From Wolpert et al., 1995). 
experimentally induced curvature. In a comparable study, Fourneret and Jeannerod required healthy humans to trace sagittal lines on a graphic tablet (Fourneret \& Jeannerod, 1998). Visual feedback of the movement was provided to the subjects through a mirror positioned above the tablet. In some trials, this feedback was shifted so that the line traced by the subjects deviated to the right or the left by a substantial amount (up to $10 \mathrm{deg}$ ). To perform a straight movement, the subjects had thus to produce a lateral response. They were able to do so quite easily. However, they kept reporting that their movement was straight in the sagittal direction. They remained unaware of their motor adjustment, suggesting, in the terms of the authors, that "normal subjects are not aware of signals generated by their own movements" (Fourneret \& Jeannerod, 1998, p. 1133). Further evidence supporting this conclusion is provided by the so-called subliminal double-step paradigm. In this paradigm, the subjects are required to "look and point" to visual targets displayed in the peripheral visual field. During saccadic gaze displacement the target location is modified. This procedure is interesting for at least three reasons. First, due to saccadic suppression, the target jump is not perceived consciously by the subjects (Matin, 1982). Second, because saccadic responses to stationary targets involve an initial saccade undershooting the target position and a secondary corrective saccade achieving accurate target acquisition (Harris, 1995), the target jump does not alter the intrinsic organization of the oculomotor system. Third, because pointing movements to stationary targets are corrected, after movement onset, when spatial information about target location is updated at the end of the saccadic shift (Desmurget, Turner, Prablanc, Russo, Alexander, \& Grafton, 2005), the target jump does not alter the intrinsic organization of the manual response. In fact, one may summarize these observations by saying that pointing directed at stationary or unconsciously displaced targets are identical from a functional point of view. The intrasaccadic modification of target location simply causes the system to generate larger corrections. What is interesting is that these corrections are not detected by the subjects who remain completely unaware of even profound changes in path curvature and individual joint trajectories (Fig. 9.3) (Desmurget, Grea, Grethe, Prablanc, Alexander, \& Grafton, 2001; Desmurget, Epstein, Turner, Prablanc, Alexander, \& Grafton, 1999; Desmurget, Gaveau, Vindras, Turner, Broussolle, \& Thobois, 2004; Prablanc \& Martin, 1992). However, it is now established that these corrections are "sensed" by the perceptual system. As shown by Johnson and Haggard (2005), (p.100)

when required to reproduce the trajectory of single and doublestep responses, after movement completion, healthy subjects perform really well. They generate straight and curved paths respectively for the single and double-step trials. In other words, the motor system "knows" that hand paths have been altered in double-step trials, but this knowledge does not reach

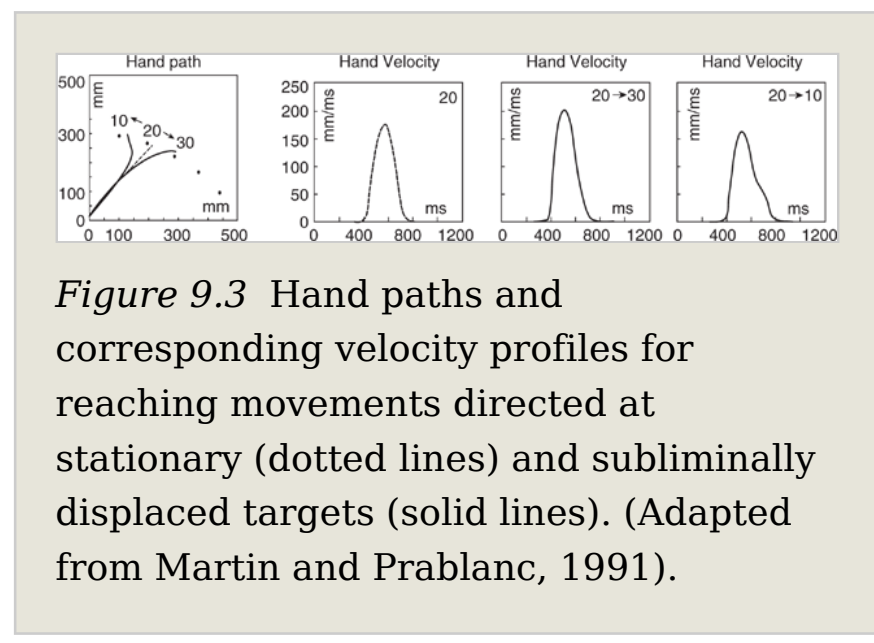


Based on data above, it is tempting to speculate that we are not aware of the kinematics and sensory details of the movement. As long as the desired state is achieved, the system does not care about the modus operandi, and no basic information about motor commands reaches consciousness. Even large discrepancies between the intended and actual sensory signals are disregarded if they can be corrected. Additional support for this view comes from adaptation studies that have compared abrupt and progressive sensory perturbations (Malfait \& Ostry, 2004; Michel, Pisella, Prablanc, Rode, \& Rossetti, 2007). In force field adaptation paradigms, for instance, when the perturbing force is introduced abruptly, the subjects cannot correct the experimentally induced error, they miss the goal and become aware of the perturbation. Now, if the same level of distortion is reached through a gradual process, on-line corrective loops can handle the error, the goal is always achieved, and the subjects remain unaware of the perturbation (Malfait \& Ostry, 2004).

To summarize, these data show that the motor system is mainly aware of its intention, in other words, of what it wants to do. As long as the goal is achieved, nothing reaches awareness about the details of the ongoing movements, even when substantial corrections have to be implemented to attain the intended state.

\section{What Is the Contribution of Afferent and Efferent Signals to Motor Awareness?}

Addressing the relative contribution of afferent and efferent signals to motor awareness amounts to addressing a simple question: how do we know we are moving? This interrogation is not new, as shown by the famous "William Debate," which opposed Wilhelm Wundt and William James, more than a century ago (Petit, 1999). For James, knowledge about our movements was constructed a posteriori on the basis of sensory reafferent inputs. For Wundt, by contrast, this knowledge was available a priori, on the basis of the motor efferent output. Although years of research have not solved the controversy, substantial progress has been made. In light of this progress a reasonable conclusion might be that both Wundt and James were partially right.

Motor Awareness and Efferent Signals 
A first line of evidence suggesting that the efferent signal is important for motor awareness comes from studies on self-recognition. In one of these studies, Tsakiris and colleagues (Tsakiris, Haggard, Franck, Mainy, \& Sirigu, 2005) investigated passive movements of the right index finger. This finger was moved through a lever operated by the left hand of the experimenter or the subject. Visual feedback about the movement was manipulated so that subjects observed their own or someone else's right hand. Self-recognition was significantly more accurate when the subjects were the authors of the action, i.e., when an efferent output was generated. This result strongly suggests that efferent information (p.101) is important for constructing motor awareness in the context of selfgenerated actions.

At a second level, strong evidence for a role of efferent signals in motor awareness comes from studies in which the subjects report being aware of performing a movement, although no sensory signal is present. In a recent experiment, Kristeva and colleagues (Kristeva, Chakarov, Wagner, SchulteMonting, \& Hepp-Reymond, 2006) re-quired a deafferented patient (GL) to perform self-paced flexions of the index finger. In control subjects, this task triggered contralateral movement-evoked potentials in the sensorimotor area. No such response was found in GL. However, this absence of sensory input did not prevent the patient from being aware of her movement. She knew that she was moving, which indicated, in the terms of the authors, that "she had a normal motor awareness" (Kristeva et al., 2006, p. 684). Of course, she had no "perceptual awareness" in the sense that she had no "feeling" about her movement. In fact, GL was "aware" that she was moving but she could not determine whether she was moving as expected. A similar observation was reported by Lafargue and colleagues, with the same patient (Lafargue, Paillard, Lamarre, \& Sirigu, 2003). These authors required GL and seven healthy subjects to produce a target force with the right hand and then match this force with the left hand. Despite variations in the motor command that were larger than in controls, GL was able to perform the task with good accuracy. She was aware, not only that she was moving, but also of the level of force that she was applying. 
Finally a third major evidence for the central origin of motor awareness comes from hemiplegic patients with anosognosia (Bisiach \& Geniniani, 1991; Orfei et al., 2007). Some of these patients fail to recognize or appreciate the severity of their deficit. Others try to "explain it away" by arguing, for instance, that they are tired or not willing to move. Others finally, claim stubbornly that they are moving, despite their paralysis. In these patients, motor awareness arises from a normal efferent command, in the absence of sensory afference. A representative example is provided by Ramachandran in a well-known review (Ramachandran, 1996, p. 124): Doctor: “Can you clap.” Patient: "Of course I can clap." Doctor: "Will you clap for me." At this point, the patient initiates clapping movements with the right hand, as if clapping with an imaginary hand near the sagittal plane. The discussion resumes. Doctor: "Are you clapping?" Patient: "Yes, I am clapping." To explain this result, it is often suggested that the brain mechanisms that normally compare the expected and actual peripheral reafferences are damaged, which prevent the subjects from knowing that they are not moving (Berti et al., 2005; Fotopoulou, Tsakiris, Haggard, Vagopoulou, Rudd, \& Kopelman, 2008). In other words, the hemiplegic patients behave like deafferented subjects: they exhibit normal motor awareness but cannot determine whether their movement is unfolding as expected. Anosognosia has a different source in both groups of patients (absence of signal Vs destruction of the comparator), but it amounts to the same type of overt deficit.

In conclusion, the data above indicate, when considered together, that the efferent motor signal is critical and sufficient for the emergence of motor awareness. This efferent contribution is often thought to rely on forward modeling (Haggard, 2005; Sirigu et al., 2004; Frith, Blakemore, \& Wolpert, 2000; Berti, Spinazzola, Pia, \& Rabuffeti, 2007; Fotopoulou et al., 2008), a process that simulates the effect of the neural command and predicts the current and final states of the motor system (Miall, Christensen, Cain, \& Stanley, 1993; Wolpert \& Flanagan, 2001; Desmurget \& Grafton, 2000, 2003). Schematically, the idea can be summarized as follows. When the subject initiates a movement, an efferent signal is issued, indicating first that the movement has started and second that the hand is at a given location, with a given velocity. Literally, this signal tells the brain that the movement is unfolding, thus leading to motor awareness. However, it does not tell the brain that the movement is unfolding as expected. This is the role of sensory reafferences.

Perceptual (Veridical) Awareness and Afferent Inputs 
There is clear evidence that sensory inputs can give rise to motor awareness. It is well known, (p.102) for instance, that passive limb displacements are easily detected and reproduced by human subjects (Klockgether, Borutta, Rapp, Spieker, \& Dichgans, 1995; Baud-Bovy \& Viviani, 2004). In the same vein, it has been shown that vibratory stimulations of the muscle tendons can give rise to illusory movements. In a very elegant study, Albert and colleagues (Albert, Bergenheim, Ribot-Ciscar, \& Roll, 2006) used a microneurographic technique to record Ia afferent messages from the six primary movers of the ankle joint, during imposed "writing like" movements. The Ia afferent pattern was then defined for each group of muscles and used as a template to pilot six small vibrators attached to the muscle tendons. Eleven different movements were considered. Following each trial, the subjects were instructed to draw with a hand-held stylus, and name, the shape of the evoked movement. The results indicated that the participants were able to achieve this task with a remarkable accuracy, thus showing that the Ia afferent feedback of a given movement evokes the illusion of the same movement (Fig. 9.4).

At first glance, this conclusion seems to contradict the evidence reported above that we are aware not of the kinematic details of the movement but of our conscious intentions (see first section). However, this apparent contradiction may be understood in reference to the process of forward modeling. Indeed, in the case of a peripheral stimulation, there is no expected input to which the actual input can be compared. As a consequence, when the sensory flow reaches the cortex, an error signal is generated. It is tempting to speculate that the inability of the motor system to deal with this signal gives rise to motor awareness. Another (nonexclusive) explanation might be related to the characteristic of passive-movement tasks. Indeed, in these tasks the subjects are generally required to pay close attention to the stimulus, which may facilitate motor awareness. As shown recently, muscle spindle sensitivity changes dramatically when attention is consciously directed to the recognition of a mechanically imposed two-dimensional movement (Hospod, Aimonetti, Roll, \& Ribot-Ciscar, 2007).

Interestingly, a recent neuroimaging study suggested that a systematic mismatch between a preserved efferent command and an absent peripheral input could be the core factor explaining conscious phantom sensations in patients with amputations of the upper limb. As reported by the authors of the study (Giraux \& Sirigu, 2003, p. S109): 
"Following peripheral injuries, motor commands can still be issued by the intact sensorimotor structures and are probably at the origin of the phantom sensations, directly or through internal "copies" of these motor commands fed back to other cortical areas such as the parietal and premotor cortices. However, since efferent motor signals produce no movement, and hence no proprioceptive input, a mismatch must occur between the normally correlated efferent and reafferent information, yielding an error signal."

In turns this error signal produces motor awareness.

Beyond the observations above, it may be worth noting that the comparison between peripheral and central signals is not straightforward from a computational point of view, even in "normal" conditions. Because of the existence of substantial delays in sensorimotor loops, this comparison has to be performed through predictive processes. Schematically, these processes are hypothesized to work as follows. Prior to movement, forward modeling is used to predict the sensory outcome of the action. This prediction is used to estimate the state of the moving limb for $70 \mathrm{~ms}$ or so (the time required to process sensory inputs; Desmurget \& Grafton, 2003). After these $70 \mathrm{~ms}$, the sensory signal becomes available. However, this signal is not related to the current hand position ( $\mathrm{t}_{\text {current }}$ ) but to the position that the hand had around movement onset $\left(t_{\text {onset }}\right)$. Thus, to be useful, the peripheral input has to be compared with the predicted input for $t_{\text {onset. }}$ This can be done if the system stores the characteristics of the expected input in a "delayed buffer" and if the delay is equivalent to the time necessary to process sensory information (Miall, Weir, Wolpert, \& Stein, 1993). If the stored prediction ( $t_{\text {onset }}$ ) matches the actual input, nothing happens. By contrast, if a discrepancy is detected, an error signal is issued and the estimation of the current motor state $\left(t_{\text {current }}\right)$ (p.103)

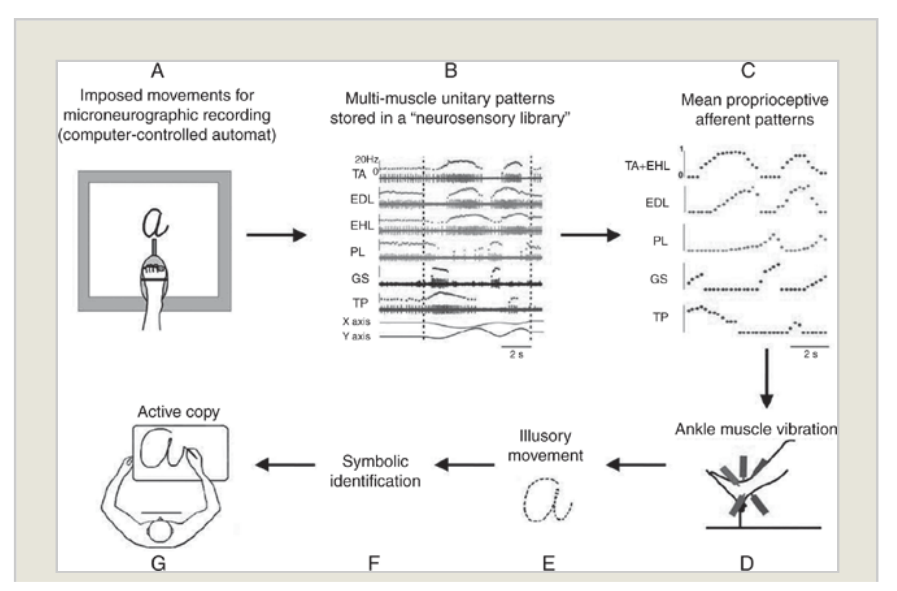


is updated accordingly. As shown in the first section of this chapter, if the goal is reached, this "cooking" remains totally unconscious. Now, if the error is too big and cannot be corrected, a conscious warning is emitted. As an illustration of this point, imagine, for instance, that a subject initiates a motor response that is blocked at movement onset by an experimental device, unbeknownst to the subject. For at least $70 \mathrm{~ms}$, this subject will be "aware" of the movement. However, after this delay, an error signal will be issued, indicating that the hand is not moving. This signal will reach consciousness, except, of course, if the process that compares the actual and predicted sensory reafferences is impaired because of a neural lesion. In this case, the subject will be aware of a movement that did not occur, as happens in hemiplegic patients with anosognosia (Berti et al., 2005).

What Are the Neural Bases of Motor Awareness?

As emphasized in the previous sections, brain damages can give rise to major abnormalities in the awareness of action. A review of the clinical literature reveals that lesions within two specific regions are especially likely to produce such abnormalities: the posterior parietal cortex and the premotor cortex.

The Posterior Parietal Cortex and Motor Awareness 
In the sections above, we provided evidence that motor awareness results from predictive computations. During the last decade, numerous studies have linked these predictive computations to the functioning of the posterior parietal cortex (PPC) (Desmurget et al., 2001; Desmurget et al., 1999; Desmurget \& Grafton, 2003; Blakemore \& (p.104) Sirigu 2003; Pellijeff, Bonilha, Morgan, McKenzie, \& Jackson, 2006; Ogawa, Inui, \& Sugio, 2007). It was shown, for instance, that on-line movement corrections to subliminally displaced visual targets (see above) are inhibited when a transcranial stimulation pulse is delivered over the PPC at movement onset (Desmurget et al., 1999). In the same vein, it was found that the process of state estimation is severely disrupted when the parietal cortex is damaged (Wolpert, Goodbody, \& Husain, 1998). A patient suffering from such damage on the left side became unable to maintain a representation of her right limbs over time. She reported feelings like "losing her right arm." Also, in the bus, she was sometimes surprised to "find" her right leg in the middle of the aisle, as other passengers tripped over her foot. A compatible observation was reported by Sirigu and colleagues in a group of patients with lesions restricted to the parietal cortex (Sirigu et al., 1996). In contrast to control subjects or an individual with a lesion to the primary motor cortex, these patients were dramatically impaired at predicting, through mental imagery, the time necessary to perform either hand gestures or visually directed pointing movements. In another study carried out by the same group (Sirigu et al., 1999), it was found that patients with parietal brain damages could sometimes present some level of anosognosia. In this study, the patients were required to perform hand movements. These movements were recorded with a video camera, and fed back to the patients through a mirror positioned above their hand (Fig. 9.5).

However, in some trials, the hand displayed in the mirror was not the real hand of the patients, but the hand of an experimenter executing a similar response. Results indicated that the patients were more impaired than healthy subjects at recognizing their own hand. Of particular interest were the trials in which the patients produced inaccurate clumsy gestures. In nearly $90 \%$ of these trials, the patients believed that they were observing their own hand when watching a smooth and accurate movement performed by the experimenter. This is not surprising, considering that the movements executed by the experimenter did closely match the conscious intention of the patients. 
From a theoretical point of view, if forward modeling underlies motor awareness and if the PPC mediates forward modeling, then two predictions can be made: (1) lesions of the PPC should induce major abnormalities in the awareness of action; (2) the subjects should become aware of their movements a few tens of milliseconds after EMG onset, when sensory signals become available. This second prediction derives from the assumption that lesion of the PPC prevents the system from anticipating the characteristics of the reafferent sensory input. Without this input, an error message is issued in response to the attempt to compare the efferent and afferent signals. This error message triggers motor awareness (see above). A pattern of response compatible with these predictions was recently reported by Sirigu and colleagues in a group of parietal patients (Sirigu et al., 2004). The authors used a paradigm initially designed by Libet and colleagues (Libet et al., 1983). In this paradigm, subjects have to fixate a spot rotating on a screen. They initiate a voluntary press-button movement with the right index finger whenever they feel a desire to do so. At random time after this movement, the rotating spot is stopped, indicating to the subjects to report where the spot was when they first felt their desire to move ("Will to move," WJudgment). Libet et al. found that the W-Judgment occurred 206 ms before EMG onset in normal subjects. A slightly longer delay (239 ms) was reported by Sirigu et al., based not on EMG onset but on the time at which the button was pressed by the subject. Interestingly, this delay was almost abolished in patients with parietal lesions. For these patients the W-Judgment occurred about 50 ms before movement onset. However, for a press-button task, the delay between EMG onset and the mechanical response can easily reach 110-120 ms (Hasbroucq, Tandonnet, Micallef-Roll, Blin, \& Possamai, 2003). This indicates that motor awareness occurred probably around 60-70 ms after actual movement onset in the parietal patients studied by Sirigu and colleagues. Such a latency is compatible with the idea that motor awareness did emerge, in the patients, not from the efferent command, but from the processing of the peripheral input, potentially by the premotor cortex. (p.105)

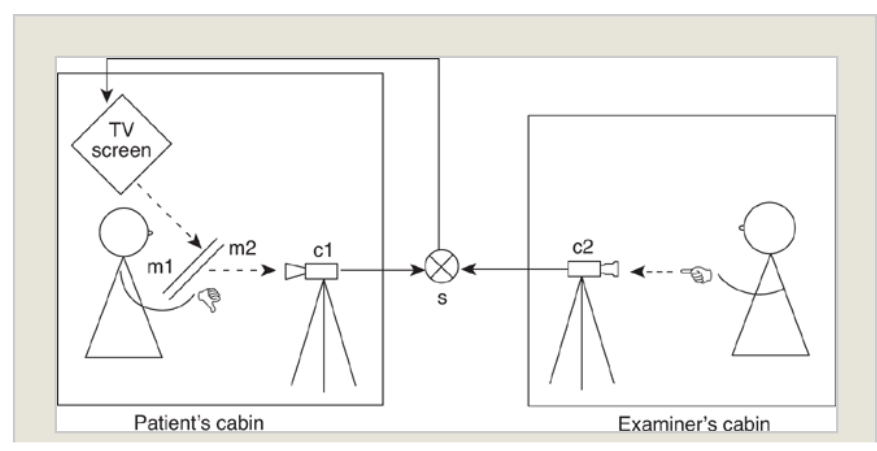


The Premotor Cortex and Veridical Motor Awareness

The main evidence that the premotor cortex is involved in veridical motor awareness comes from a lesion mapping study (Berti et al., 2005). In this study, Berti and colleagues investigated the anatomical distribution of brain lesions in right-brain-damaged patients with anosognosia for hemiplegia. As previously stated, these patients stubbornly deny their motor impairment. They keep claiming that they can move their paralyzed limb with no deficit. Berti and colleagues identified the premotor cortex (area 6) as the most frequently damaged area in these patients. It was concluded that this region monitors the actual movement by comparing the actual and expected sensory reafferences. This hypothesis is consistent with the fact that the premotor cortex receives sensory reafferences about the ongoing movement (Hummelsheim, Bianchetti, Wiesendanger, \& Wiesendanger, 1988; Scott, Sergio, \& Kalaska, 1997; Fogassi, Raos, Franchi, Gallese, Luppino, \& Matelli, 1999; Raos, Franchi, Gallese, \& Fogassi, 2003). However, there is little evidence in the literature indicating that this region is involved in forward modeling. Most studies suggest that this process is more likely to rely on the functioning of the cerebellum and the parietal cortex (Wolpert et al., 1998; Desmurget et al., 2001; Desmurget et al., 1999; Blakemore \& Sirigu, 2003; Miall et al., 2007; Miall \& King, 2008). Further studies will be necessary to address the origin of this discrepancy.

\section{Conclusions}

In this chapter, we have briefly reviewed evidence that the motor system is mainly aware of its intention. As long as the goal is achieved, nothing reaches awareness about the kinematic details of the ongoing movements, even when substantial corrections have to be implemented to attain the intended state. Also, we showed that motor awareness relies mainly on the central predictive computations carried out within the posterior parietal cortex. The outcome of these computations is contrasted with the peripheral reafferent input to build a veridical motor awareness. Some evidence exists that this process involves the premotor areas.

\section{References}

\section{Bibliography references:}

Albert, F., Bergenheim, M., Ribot-Ciscar, E., \& Roll, J. P. (2006). The Ia afferent feedback of a given movement evokes the illusion of the same movement when returned to the subject via muscle tendon vibration. Experimental Brain

Research, 172, 163-174. 
Baud-Bovy, G., \& Viviani, P. (2004). Amplitude and direction errors in kinesthetic pointing. Experimental Brain Research, 157, 197-214.

(p.106) Bergson, H. (1888/2007). Essai sur les données immédiates de la conscience. Paris: Puf.

Berti, A., Bottini, G., Gandola, M., Pia, L., Smania, N., Stracciari, A., et al. (2005). Shared cortical anatomy for motor awareness and motor control. Science, 309, 488-491.

Berti, A., Spinazzola, L., Pia, L., \& Rabuffeti, M. (2007). Motor awareness and motor intention in anosognosia for hemiplegia. In P. Haggard, Y. Rossetti, \& M. Kawato (Eds.), Sensorimotor foundations of higher cognition series: Attention and performance XXII. New York: Oxford University Press.

Bisiach, E., \& Geniniani, G. (1991). Anosognosia related to hemiplegia and heminopia. In G. P. Prigatano \& D. L. Scahcter (Eds.), Awareness of deficit after brain injury (pp. 17-39). New York: Oxford University Press.

Blakemore, S. J., \& Sirigu, A. (2003). Action prediction in the cerebellum and in the parietal lobe. Experimental Brain Research, 153, 239-245.

Descartes, R. (1641/1992). Méditations métaphysiques. Paris: Flammarion.

Desmurget, M., Epstein, C. M., Turner, R. S., Prablanc, C., Alexander, G. E., \& Grafton, S. T. (1999). Role of the posterior parietal cortex in updating reaching movements to a visual target. Nature Neuroscience, 2, 563-567.

Desmurget, M., Gaveau, V., Vindras, P., Turner, R. S., Broussolle, E., \& Thobois, S. (2004). On-line motor control in patients with Parkinson's disease. Brain, 127, 1755-1773.

Desmurget, M., \& Grafton, S. (2000). Forward modeling allows feedback control for fast reaching movements. Trends in Cognitive Sciences, 4, 423-431.

Desmurget, M., \& Grafton, S. (2003). Feedback or forward control: End of a dichotomie. In S. Johnson (Ed.), Cognitive neuroscience perspectives on the problem of intentional action (pp. 289-338). Boston: MIT Press.

Desmurget, M., Grea, H., Grethe, J. S., Prablanc, C., Alexander, G. E., \& Grafton, S. T. (2001). Functional anatomy of nonvisual feedback loops during reaching: A positron emission tomography study. Journal of Neuroscience, 21, 2919-2928.

Desmurget, M., Turner, R. S., Prablanc, C., Russo, G. S., Alexander, G. E., \& Grafton, S. T. (2005). Updating target location at the end of an orienting saccade affects the characteristics of simple point-to-point movements. Journal of Experimental Psychology: Human Perception and Performance, 31, 1510-1536. 
Dijksterhuis, A., \& Bargh, J. A. (2001). The perception-behavior expressway: Automatic effects of social perception on social behavior. Advances in Experimental Social Psychology, 33, 1-40.

Fogassi, L., Raos, V., Franchi, G., Gallese, V., Luppino, G., \& Matelli, M. (1999). Visual responses in the dorsal premotor area F2 of the macaque monkey. Experimental Brain Research, 128, 194-199.

Fotopoulou, A., Tsakiris, M., Haggard, P., Vagopoulou, A., Rudd, A., \& Kopelman, M. (2008). The role of motor intention in motor awareness: An experimental study on anosognosia for hemiplegia. Brain, 131, 3432-3442.

Fourneret, P., \& Jeannerod, M. (1998). Limited conscious monitoring of motor performance in normal subjects. Neuropsychologia, 36, 1133-1140.

Frith, C. D., Blakemore, S. J., \& Wolpert, D. M. (2000). Abnormalities in the awareness and control of action. Philosophical Transactions of the Royal Society B: Biological Sciences, 355, 1771-1788.

Giraux, P., \& Sirigu, A. (2003). Illusory movements of the paralyzed limb restore motor cortex activity. Neuroimage, 20(Suppl. 1), S107-S111.

Goodale, M. A., Pelisson, D., \& Prablanc, C. (1986). Large adjustments in visually guided reaching do not depend on vision of the hand or perception of target displacement. Nature, 320, 748-750.

Graziano, M. S., Taylor, C. S., \& Moore, T. (2002). Complex movements evoked by microstimulation of precentral cortex. Neuron, 34, 841-851.

Haggard, P. (2005). Conscious intention and motor cognition. Trends in Cognitive Sciences, 9, 290-295.

Haggard, P. (2008). Human volition: Towards a neuroscience of will. Nature Reviews Neuroscience, 9, 934-946.

Haggard, P., Clark, S., \& Kalogeras, J. (2002). Voluntary action and conscious awareness. Nature Neuroscience, 5, 382-385.

Haggard, P., \& Eimer, M. (1999). On the relation between brain potentials and the awareness of voluntary movements. Experimental Brain Research, 126, 128133.

Harris, C. M. (1995). Does saccadic undershoot minimize saccadic flight-time? A Monte-Carlo study. Vision Research, 35, 691-701.

(p.107) Hasbroucq, T., Tandonnet, C., Micallef-Roll, J., Blin, O., \& Possamai, C. A. (2003). An electromyographic analysis of the effect of levodopa on the response time of healthy subjects. Psychopharmacology (Berlin), 165, 313-316. 
Hospod, V., Aimonetti, J. M., Roll, J. P., \& Ribot-Ciscar, E. (2007). Changes in human muscle spindle sensitivity during a proprioceptive attention task. Journal of Neuroscience, 27, 5172-5178.

Hummelsheim, H., Bianchetti, M., Wiesendanger, M., \& Wiesendanger, R. (1988). Sensory inputs to the agranular motor fields: A comparison between precentral, supplementary-motor and premotor areas in the monkey. Experimental Brain Research, 69, 289-298.

Johnson, H., \& Haggard, P. (2005). Motor awareness without perceptual awareness. Neuropsychologia, 43, 227-237.

Klockgether, T., Borutta, M., Rapp, H., Spieker, S., \& Dichgans, J. (1995). A defect of kinesthesia in Parkinson's disease. Movement Disorders, 10, 460-465.

Kristeva, R., Chakarov, V., Wagner, M., Schulte-Monting, J., \& Hepp-Reymond, M. C. (2006). Is the movement-evoked potential mandatory for movement execution? A high-resolution EEG study in a deafferented patient. Neuroimage, $31,677-685$.

Lafargue, G., Paillard, J., Lamarre, Y., \& Sirigu, A. (2003). Production and perception of grip force without proprioception: is there a sense of effort in deafferented subjects? European Journal of Neuroscience, 17, 2741-2749.

Libet, B., Gleason, C. A., Wright, E. W., \& Pearl, D. K. (1983). Time of conscious intention to act in relation to onset of cerebral activity (readiness-potential): The unconscious initiation of a freely voluntary act. Brain, 106(3), 623-642.

Malfait, N., \& Ostry, D. J. (2004). Is interlimb transfer of force-field adaptation a cognitive response to the sudden introduction of load? Journal of Neuroscience, 24, 8084-8089.

Matin, E. (1982). Saccadic suppression and the dual mechanism theory of direction constancy. Vision Research, 22, 335-336.

Miall, R. C., Christensen, L. O., Cain, O., \& Stanley, J. (2007). Disruption of state estimation in the human lateral cerebellum. PLoS Biology, 5, e316.

Miall, R. C., \& King, D. (2008). State estimation in the cerebellum. Cerebellum, 7, 572-576.

Miall, R. C., Weir, D. J., Wolpert, D. M., \& Stein, J. F. (1993). Is the cerebellum a Smith predictor? Journal of Motor Behavior, 25, 203-216. 
Michel, C., Pisella, L., Prablanc, C., Rode, G., \& Rossetti, Y. (2007). Enhancing visuomotor adaptation by reducing error signals: Single-step (aware) versus multiple-step (unaware) exposure to wedge prisms. Journal of Cognitive Neuroscience, 19, 341-350.

Moore, J., \& Haggard, P. (2008). Awareness of action: Inference and prediction. Consciousness and Cognition, 17, 136-144.

Ogawa, K., Inui, T., \& Sugio, T. (2007). Neural correlates of state estimation in visually guided movements: An event-related fMRI study. Cortex, 43, 289-300.

Orfei, M. D., Robinson, R. G., Prigatano, G. P., Starkstein, S., Rüsch, N., Bria, P., et al. (2007). Anosognosia for hemiplegia after stroke is a multifaceted phenomenon: A systematic review of the literature. Brain, 130, 3075-3090.

Pellijeff, A., Bonilha, L., Morgan, P. S., McKenzie, K., \& Jackson, S. R. (2006). Parietal updating of limb posture: An event-related fMRI study. Neuropsychologia, 44, 2685-2690.

Petit, J.-L. (1999). Constitution by movement: Husserl in light of recent neurobiological findings. In F. Petitot, F. J. Varela, B. Pachoud, \& J.-M. Roy (Eds.), Naturalizing phenomenology: Issues in contemporary phenomenology and cognitive science (pp. 220-245). Stanford, CA: Stanford University Press.

Prablanc, C., \& Martin, O. (1992). Automatic control during hand reaching at undetected two-dimensional target displacements. Journal of Neurophysiology, $67,455-469$.

Ramachandran, V. S. (1996). What neurological syndromes can tell us about human nature: Some lessons from phantom limbs, capgras syndrome, and anosognosia. Cold Spring Harbor Symposia on Quantitative Biology, 61, 115134.

Ramachandran, V. S., \& Hirstein, W. (1998). The perception of phantom limbs: The D. O. Hebb Lecture. Brain, 121(9), 1603-1630.

Raos, V., Franchi, G., Gallese, V., \& Fogassi, L. (2003). Somatotopic organization of the lateral part of area F2 (dorsal premotor cortex) of the macaque monkey. Journal of Neurophysiology, 89, 1503-1518.

Scepkowski, L. A., \& Cronin-Golomb, A. (2003). The alien hand: Cases, categorizations, and anatomical correlates. Behavioral and Cognitive Neuroscience Reviews, 2, 261-277. 
(p.108) Scott, S. H., Sergio, L. E., \& Kalaska, J. F. (1997). Reaching movements with similar hand paths but different arm orientations: Vol. 2. Activity of individual cells in dorsal premotor cortex and parietal area 5. Journal of Neurophysiology, 78, 2413-2426.

Sirigu, A., Daprati, E., Ciancia, S., Giraux, P., Nighoghossian, N., Posada, A., et al. (2004). Altered awareness of voluntary action after damage to the parietal cortex. Nature Neuroscience, 7, 80-84.

Sirigu, A., Daprati, E., Pradat-Diehl, P., Franck, N., \& Jeannerod, M. (1999). Perception of self-generated movement following left parietal lesion. Brain, 122(10), 1867-1874.

Sirigu, A., Duhamel, J. R., Cohen, L., Pillon, B., Dubois, B., \& Agid, Y. (1996). The mental representation of hand movements after parietal cortex damage. Science, $273,1564-1568$.

Spinoza, B. (1677/1994). L'éthique. Paris: Gallimard.

Tsakiris, M., Haggard, P., Franck, N., Mainy, N., \& Sirigu, A. (2005). A specific role for efferent information in self-recognition. Cognition, 96, 215-231.

Turner, R. S., Desmurget, M., Grethe, J., Crutcher, M. D., \& Grafton, S. T. (2003). Motor subcircuits mediating the control of movement extent and speed. Journal of Neurophysiology, 90, 3958-3966.

Watson, J. B. (1913). Psychology as the behaviorist views it. Psychological Review, 20, 158-177.

Wing, A. M., Flanagan, J. R., \& Richardson, J. (1997). Anticipatory postural adjustments in stance and grip. Experimental Brain Research, 116, 122-130.

Wolpert, D. M., \& Flanagan, J. R. (2001). Motor prediction. Current Biology, 11, R729-R732.

Wolpert, D. M., Ghahramani, Z., \& Jordan, M. I. (1995). Are arm trajectories planned in kinematic or dynamic coordinates? An adaptation study. Experimental Brain Research, 103, 460-470.

Wolpert, D. M., Goodbody, S. J., \& Husain, M. (1998). Maintaining internal representations: The role of the human superior parietal lobe. Nature Neuroscience, 1, 529-533.

Yarbus, A. L. (1967). Eye movements and vision. New York: Plenum Press.

\section{Access brought to you by:}

